\title{
Year-round vitamin D deficiency among Saudi female out-patients
}

\author{
Raed M Kanan ${ }^{1, *}$, Yousef M Al Saleh², Hana M Fakhoury ${ }^{3}$, Maysoon Adham ${ }^{4}$, \\ Saleh Aljaser ${ }^{2}$ and Waleed Tamimi ${ }^{1,5}$ \\ ${ }^{1}$ College of Applied Medical Sciences, King Saud Bin Abdulaziz University for Health Sciences, PO Box 2490, \\ Riyadh, Mail code 3129/Postal Code 11426, Saudi Arabia: ${ }^{2}$ Division of Endocrinology, Department of \\ Medicine, King Abdulaziz Medical City, Riyadh, Saudi Arabia: ${ }^{3}$ College of Medicine, King Saud Bin Abdulaziz \\ University for Health Sciences, Riyadh, Saudi Arabia: ${ }^{4}$ Division of OB/GYN, Department of Medicine, King \\ Abdulaziz Medical City, Riyadh, Saudi Arabia: ${ }^{5}$ Division of Clinical Chemistry, Department of Pathology \& \\ Laboratory Medicine, King Abdulaziz Medical City, Riyadh, Saudi Arabia
}

Submitted 15 January 2012: Final revision received 4 April 2012: Accepted 30 April 2012: First published online 13 June 2012

\begin{abstract}
Objective: The aim of the present study was to investigate vitamin D status among female out-patients in Saudi Arabia during the summer and winter seasons. Design: Data were retrospectively collected using medical record abstraction. Setting: A multidisciplinary hospital in Riyadh between January and December 2009. Subjects: Saudi females (age $\geq 19$ years; $n$ 1556) attending out-patient clinics for various complaints comprised the studied population. The population was subdivided into two groups depending on the date of their visit where blood samples were collected: summer ( $n$ 659) and winter groups ( $n$ 897). The summer group was further subdivided into premenopausal (age $19-49$ years; $n$ 425) and postmenopausal subgroups (age $\geq 50$ years; $n$ 234). Similarly, the winter group was subdivided into premenopausal ( $n$ 543) and postmenopausal subgroups ( $n$ 354). Serum levels of 25-hydroxyvitamin D $(25(\mathrm{OH}) \mathrm{D})$ were measured using HPLC. Results: The prevalence of vitamin D deficiency $(25(\mathrm{OH}) \mathrm{D}<50 \mathrm{nmol} / \mathrm{l})$ was high in both premenopausal and postmenopausal groups (80\% and 68\%, respectively) during the summer, as well as during the winter ( $85 \%$ and $76 \%$, respectively). Conclusions: A high prevalence of vitamin D deficiency among Saudi female out-patients was observed throughout the year despite the routine supplementation with $10-20 \mu \mathrm{g}$ vitamin $\mathrm{D}_{3}$ for postmenopausal women. Clinicians should seriously consider determining the vitamin D status of Saudi females routinely and prescribing them proper supplementation.
\end{abstract}

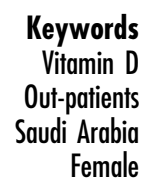

Vitamin D is a vitamin-hormone which is not only crucial for Ca homeostasis but also to general health ${ }^{(1)}$. Vitamin D is obtained from sun exposure, food and supplementation. While it is well known that severe vitamin D deficiency leads to osteomalacia and rickets, and that mild to moderate deficiency can result in osteoporosis and an increased risk of fractures ${ }^{(2)}$, more recent research has been linking vitamin D deficiency to autoimmune disorders, CVD and cancers ${ }^{(3,4)}$.

Dietary sources of vitamin D are limited to few foods, such as fish oils, fatty fish, eggs, organ meat and UVirradiated mushrooms. In Saudi Arabia, fortified foods are limited to very few dairy products and cereals ${ }^{(5)}$. Therefore, the major source of vitamin $\mathrm{D}$ is via exposure of uncovered skin to solar UV-B radiation ${ }^{(6)}$. UV rays are strongest in areas close to the Equator because: (i) the sun is directly over the Equator and thus the UV rays travel a shorter distance through the atmosphere to reach the surface of the Earth; and (ii) the ozone layer, which absorbs UV radiation, is naturally thinner in these areas ${ }^{(7)}$. It has been shown that seasons other than summer (i.e. winter, autumn and spring) can contribute to vitamin D deficiency ${ }^{(8-10)}$, even with a daily supplement regimen of vitamin $\mathrm{D}_{3}(7 \cdot 5 \mu \mathrm{g})$ taken for 12 months $^{(10)}$.

Although one would presume that living at lower latitudes would guarantee protection against vitamin D deficiency, a previous study on the adult population residing in south Florida has shown otherwise ${ }^{(11)}$. Furthermore, vitamin D deficiency is common in India, Australia, Brazil and the Middle East, because of cultural habits and sun avoidance ${ }^{(12-17)}$.

Our goal was to establish the prevalence of vitamin D deficiency and to assess seasonal variations in vitamin D levels in adult Saudi female out-patients in Riyadh, Saudi 
Arabia $\left(24^{\circ} 42^{\prime} \mathrm{N}\right)$, an area of year-round sunny weather. The study was conducted in both postmenopausal and premenopausal women in order to investigate the effect of menopausal status on vitamin $\mathrm{D}$ levels.

\section{Experimental methods}

Data were collected retrospectively using medical record abstraction for the present cross-sectional study of adult female out-patients ( $\geq 19$ years). Values of serum levels of vitamin $\mathrm{D}$ were extracted for 1556 women attending out-patient care at King Abdulaziz Medical City (KAMC), which is part of the National Guard Health Affairs in Riyadh, between January 2009 and December 2009. The patients were attending various clinics at the hospital which included rheumatology, neurology, orthopaedic, internal medicine and endocrinology clinics, among many others. In addition, the KAMC has a number of clinics which offer primary care to the community. Women attending clinics for issues related to their bone health were excluded from the study. Information related to the date of birth and the clinics the patients were attending were extracted from the record. Women were subdivided into two groups: patients treated during the summer (June, July and August, $n$ 659) and patients treated during the winter (January, February and March, $n$ 897). The summer group (group A) was further subdivided into premenopausal (group A1, age 19-49 years; $n$ 425) and postmenopausal subgroups (group A2, age $\geq 50$ years, $n$ 234). The winter group (group B) was also subdivided into premenopausal (group B1, $n 543$ ) and postmenopausal (group B2, $n$ 354) subgroups. The age of 50 years was used as a cut-off point for determining menopausal status ${ }^{(18)}$.

Serum levels of total 25-hydroxyvitamin D (25(OH)D; sum of $\mathrm{D}_{2}$ and $\mathrm{D}_{3}$ ) were measured in the central laboratory of KAMC using HPLC. The analysis was performed on HPLC columns ( $\mathrm{CV}=3 \%)$ from Chromsystems (Munich, Germany). Results were expressed in nmol/l. Vitamin D deficiency was described for levels of 25(OH)D falling below $<50 \mathrm{nmol} / \mathrm{l}^{(19)}$, whereas insufficiency was at $50-75 \mathrm{nmol} / \mathrm{l}$, and optimum level was at $76-200 \mathrm{nmol} / \mathrm{l}$.

\section{Statistical analysis}

Data were analysed using the SPSS for Windows statistical software package version $15 \cdot 0$ and Microsoft Excel $^{\mathrm{TM}}$ 2007. Age was expressed as mean and standard deviation,
$25(\mathrm{OH}) \mathrm{D}$ levels were expressed as means with their standard errors, and prevalence of vitamin D deficiency was calculated as percentage. Comparison of prevalence of vitamin $\mathrm{D}$ deficiency among groups was done using the $\chi^{2}$ test, whereas comparison of vitamin D levels was performed using the unpaired $t$ test. A $P$ value of $<0.05$ was considered significant.

\section{Results}

The patients' mean age was $44 \cdot 4$ (SD 16.1) years for the summer group and $46 \cdot 1$ (SD 15.9) years for the winter group. We found that our studied population had a high prevalence of vitamin D deficiency in both seasons (Table 1). Indeed, during the summer, the prevalence of vitamin $\mathrm{D}$ deficiency $(25(\mathrm{OH}) \mathrm{D}<50 \mathrm{nmol} / \mathrm{l})$ in premenopausal and postmenopausal patients was $80 \%$ and $68 \%$, respectively. This high prevalence of vitamin D deficiency was even more pronounced in the winter season $(85 \%$ and $76 \%$ for premenopausal and postmenopausal, respectively). This seasonal variation was statistically significant only in the postmenopausal group, where the prevalence of vitamin D deficiency was significantly higher in the winter compared with the summer $(P=0 \cdot 035)$.

The premenopausal group had a higher level of $25(\mathrm{OH}) \mathrm{D}$ in the summer $(33.3$ (se 1.65$) \mathrm{nmol} / \mathrm{l})$ than in the winter $(28.5$ (se 1.16$) \mathrm{nmol} / \mathrm{l} ; P<0 \cdot 05)$. Similarly, the postmenopausal group had a higher level of $25(\mathrm{OH}) \mathrm{D}$ in summer $(44 \cdot 4$ (SE $2 \cdot 3) \mathrm{nmol} / \mathrm{l})$ compared with the winter (36.3 (se 1.51) nmol/l; Table 2 and Fig. 1). Moreover, in the summer season, the postmenopausal group ( $44 \cdot 4$ (SE $2 \cdot 3) \mathrm{nmol} / \mathrm{l}$ ) had a significantly higher level of 25(OH)D compared with the premenopausal group (33.3 (SE 1.65) nmol/1; $P<0 \cdot 05)$. A similar trend was also observed in the winter, where the postmenopausal group (36.3 (SEм 1.51) $\mathrm{nmol} / \mathrm{l})$ had a significantly higher level of $25(\mathrm{OH}) \mathrm{D}$ compared with the premenopausal group (28.5 (sE 1.16) nmol/l; $P<0 \cdot 05$; Table 2 and Fig. 2).

In summary, we found a high prevalence of vitamin $\mathrm{D}$ deficiency year-round among Saudi female out-patients. However, 25(OH)D levels were relatively higher in summer for both premenopausal and postmenopausal patients. It is noteworthy that postmenopausal patients had slightly higher levels of $25(\mathrm{OH}) \mathrm{D}$ compared with their premenopausal counterparts.

Table 1 Comparison of vitamin D status among premenopausal and postmenopausal women in summer and winter groups: Saudi female out-patients, January-December 2009

\begin{tabular}{|c|c|c|c|c|c|}
\hline & \multicolumn{2}{|c|}{ Group A (summer) } & \multicolumn{2}{|c|}{ Group B (winter) } & \multirow[b]{2}{*}{$P$ value } \\
\hline & $\begin{array}{l}\text { Group A1 ( } n \text { 425; } \\
\text { premenopausal) }\end{array}$ & $\begin{array}{l}\text { Group A2 ( } n \text { 234; } \\
\text { postmenopausal) }\end{array}$ & $\begin{array}{l}\text { Group B1 ( } n 543 ; \\
\text { premenopausal) }\end{array}$ & $\begin{array}{l}\text { Group B2 ( } n \text { 354; } \\
\text { postmenopausal) }\end{array}$ & \\
\hline Deficient (\%) & 80 & 68 & 85 & 76 & $P=0.035(\mathrm{~A} 2 v . \mathrm{B} 2)$ \\
\hline Insufficient (\%) & 8 & 12 & 9 & 15 & $P>0.05$ \\
\hline Optimal (\%) & 11 & 20 & 6 & 9 & $P>0.05$ \\
\hline
\end{tabular}




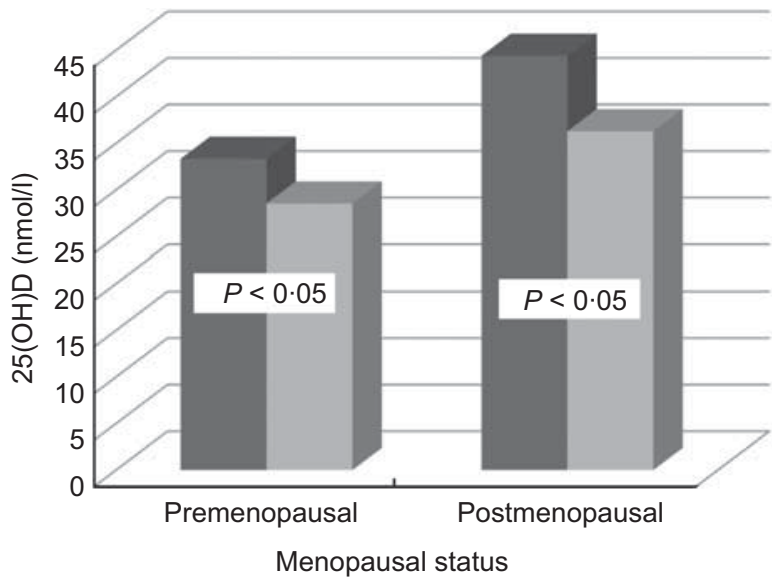

Fig. 1 Comparison of total 25-hydroxyvitamin D (25(OH)D) levels between premenopausal (age 19-49 years) and postmenopausal (age $\geq 50$ years) groups according to season ( $\square$, summer, premenopausal $n 425$, postmenopausal $n 234$; $\square$, winter, premenopausal $n 543$, postmenopausal $n$ 354): Saudi female out-patients, January-December 2009

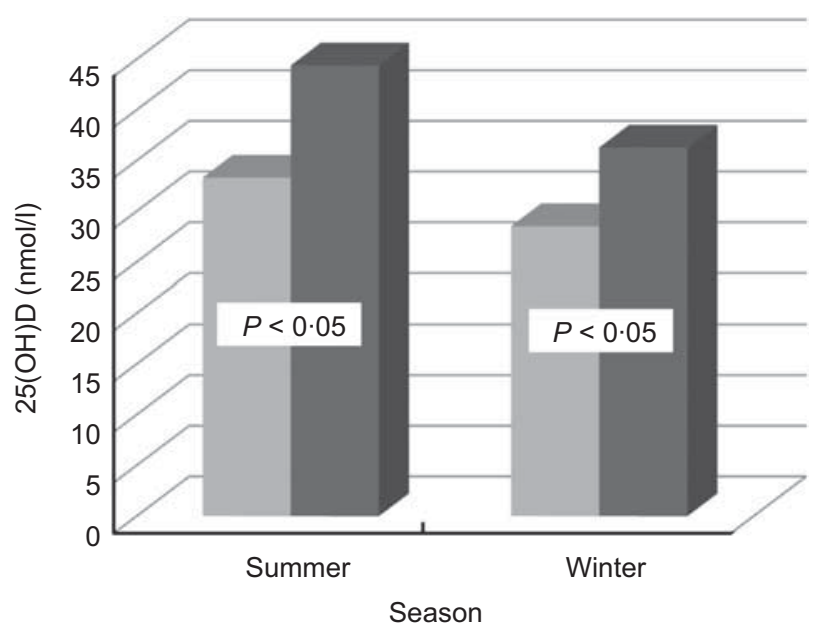

Fig. 2 Comparison of total 25-hydroxyvitamin $\mathrm{D}(25(\mathrm{OH}) \mathrm{D})$ between summer and winter groups according to menopausal status ( $\square$, premenopausal, age $19-49$ years, $n 425$ in summer, $n 543$ in winter; $\square$, postmenopausal, age $\geq 50$ years, $n 234$ in summer, $n 354$ in winter): Saudi female out-patients, JanuaryDecember 2009

\section{Discussion}

The high prevalence of vitamin D deficiency in the Kingdom of Saudi Arabia has been well established in several subpopulations ${ }^{(20-28)}$. Moreover, this micronutrient deficiency has been well documented across the entire Middle East and the developing world ${ }^{(16,29-33)}$. However, no such cohort of female out-patients was investigated previously.

The highlight of the present study is the discovery that there is a year-round high prevalence of vitamin D 
deficiency among Saudi female out-patients regardless of their menopausal status. The study subjects represent a population who has free access to optimal health care and all complementary benefits including routine supplementation of $\mathrm{Ca}$ and vitamin $\mathrm{D}$ for postmenopausal women.

While regular exposure to sunlight is considered an effective prophylaxis against vitamin D deficiency ${ }^{(34)}$, studies in regions located at low latitude with abundant sunlight have also shown a high prevalence of vitamin D deficiency $^{(12-17)}$. These findings have been explained as being mostly due to the region's customary clothing and sun avoidance ${ }^{(33)}$. In addition, scientists have suggested that in the Saudi population, vitamin D deficiency among women may be due to lack of public awareness ${ }^{(23)}$. However, hot desert climate, social and religious habits all act against sun exposure. Moreover, the widespread occurrence of obesity and darker skin in the region increase the length of time required to achieve optimum vitamin D level from sun exposure.

An interesting finding in our study was that postmenopausal patients had relatively higher vitamin D levels, which is in contradiction with the previous finding in another study on healthy Saudi women ${ }^{(26)}$. Having our study groups as out-patients may give an explanation for this phenomenon, where many clinicians tend to prescribe $1 \mathrm{~g} \mathrm{Ca}$ and $10-20 \mu \mathrm{g}$ vitamin D for postmenopausal women as a protection against osteoporosis, without assessing their vitamin D status.

The high prevalence of vitamin D deficiency in Saudis has been reported in the literature since the $1980 \mathrm{~s}^{(24,35)}$. This deficiency remains unresolved and might have been accentuated in recent times by increased sun avoidance caused by many factors including more urbanized lifestyles and aesthetic reasons, where the culture tends to favour fair skin which is not suntanned. Therefore, even in the privacy of their own homes, women from this culture tend to avoid sun exposure.

The authors acknowledge some limitations to the study. For example, our studied population consisted of patients with mild to severe illnesses of various lengths. Therefore, the pathological conditions or treatment regimen could have contributed to the lower serum 25(OH)D levels. Nevertheless, severe hepatic or renal failure was very rare in our patients. Another limitation is the absence of comprehensive data on the levels of parathyroid hormone. However, parathyroid hormone values were obtained for some but not all patients (data not shown). Preliminary observations indicate that not all patients with vitamin D deficiency had elevated parathyroid hormone, a finding which requires further investigation.

The strengths of the study include, but are not limited to, a sample size that is large enough to infer generalizations across the entire population with the same criteria. Another major strength in our study is the use of the gold standard method of HPLC for the quantification of $25(\mathrm{OH}) \mathrm{D}$.

\section{Conclusions}

The prevalence of vitamin D deficiency among Saudi women is alarmingly high. In a region with abundant sunshine throughout the year, this deficiency is independent of seasonal influence. Clinicians should have an active role in screening and treating this widespread deficiency which has serious impacts on health that go far beyond bone health. Clinicians seeing these patients must make an increased effort to prevent vitamin D deficiency by checking vitamin D levels and educating these patients about the benefits of sun exposure. Clinicians should also attempt to correct these deficiencies by prescribing vitamin D supplements at the appropriate dosage.

\section{Acknowledgements}

This research did not receive any grant from any funding agency in the public, commercial or not-for-profit sectors. The authors declare having no conflict of interest. All authors have participated sufficiently in the intellectual content, conception and design of this work or the analysis and interpretation of the data, as well as the writing of the manuscript, and have approved the final version of the submitted manuscript.

\section{References}

1. Holick MF (2004) Sunlight and vitamin D for bone health and prevention of autoimmune diseases, cancers, and cardiovascular disease. Am J Clin Nutr 80, 6 Suppl., 1678S-1688S.

2. Thomas MK \& Demay MB (2000) Vitamin D deficiency and disorders of vitamin D metabolism. Endocrinol Metab Clin North Am 29, 611-627, viii.

3. Holick MF (2011) Vitamin D: a d-lightful solution for health. J Investig Med 59, 872-880.

4. Stokstad E (2003) Nutrition. The vitamin D deficit. Science 302, 1886-1888.

5. Madani KA, Al-Amoudi NS \& Kumosani TA (2000) The state of nutrition in Saudi Arabia. Nutr Health 14, 17-31.

6. Holick MF (2007) Vitamin D deficiency. N Engl J Med 357, 266-281.

7. Frederick JE (2002) Ozone: ozone as a UV filter. Encyclopedia Atmos Sci 4, 1621-1627. doi:10.1016/B0-12227090-8/00296-7

8. Mavroeidi A, O’Neill F, Lee PA et al. (2010) Seasonal 25-hydroxyvitamin D changes in British postmenopausal women at 57 degrees $\mathrm{N}$ and 51 degrees N: a longitudinal study. I Steroid Biochem Mol Biol 121, 459-461.

9. Vanlint SJ, Morris HA, Newbury JW et al. (2011) Vitamin D insufficiency in Aboriginal Australians. Med J Aust 194, $131-134$.

10. Manios Y, Moschonis G \& Lyritis GP (2011) Seasonal variations of vitamin D status in Greek postmenopausal women receiving enriched dairy products for 30 months: the Postmenopausal Health Study. Eur J Clin Nutr 65, 412-414.

11. Levis S, Gomez A, Jimenez C et al. (2005) Vitamin d deficiency and seasonal variation in an adult South Florida population. J Clin Endocrinol Metab 90, 1557-1562. 
12. Agarwal N \& Arya SC (2011) Vitamin D levels in pregnant women and newborns at a private tertiary care hospital in Delhi, India. Int J Gynaecol Obstet 113, 240-241.

13. Goswami R, Gupta N, Goswami D et al. (2000) Prevalence and significance of low 25-hydroxyvitamin D concentrations in healthy subjects in Delhi. Am J Clin Nutr 72, 472-475.

14. Nowson CA, Diamond TH, Pasco JA et al. (2004) Vitamin D in Australia. Issues and recommendations. Aust Fam Physician 33, 133-138.

15. Unger MD, Cuppari L, Titan SM et al. (2010) Vitamin D status in a sunny country: where has the sun gone? Clin Nutr 29, 784-788.

16. Hamilton B, Grantham J, Racinais S et al. (2010) Vitamin D deficiency is endemic in Middle Eastern sportsmen. Public Health Nutr 13, 1528-1534.

17. Gannage-Yared MH, Chemali R, Sfeir C et al. (2005) Dietary calcium and vitamin D intake in an adult Middle Eastern population: food sources and relation to lifestyle and PTH. Int J Vitam Nutr Res 75, 281-289.

18. Frommer DJ (1964) Changing age of the menopause. $\mathrm{Br}$ Med J 2, 349-351.

19. Holick MF, Binkley NC, Bischoff-Ferrari HA et al. (2011) Evaluation, treatment, and prevention of vitamin D deficiency: an Endocrine Society clinical practice guideline. J Clin Endocrinol Metab 96, 1911-1930.

20. Elsammak MY, Al-Wosaibi AA, Al-Howeish A et al. (2010) Vitamin D deficiency in Saudi Arabs. Horm Metab Res 42, 364-368.

21. Al-Daghri NM, Al-Attas OS, Al-Okail MS et al. (2010) Severe hypovitaminosis D is widespread and more common in non-diabetics than diabetics in Saudi adults. Saudi Med J 31, 775-780.

22. Al-Turki HA, Sadat-Ali M, Al-Elq AH et al. (2008) 25Hydoxyvitamin D levels among healthy Saudi Arabian women. Saudi Med J 29, 1765-1768.

23. Siddiqui AM \& Kamfar HZ (2007) Prevalence of vitamin D deficiency rickets in adolescent school girls in Western region, Saudi Arabia. Saudi Med J 28, 441-444.
24. Sedrani SH, Elidrissy AW \& El Arabi KM (1983) Sunlight and vitamin D status in normal Saudi subjects. Am J Clin Nutr 38, 129-132.

25. Christie FT \& Mason L (2011) Knowledge, attitude and practice regarding vitamin $\mathrm{D}$ deficiency among female students in Saudi Arabia: a qualitative exploration. Int $J$ Rheum Dis 14, e22-e29.

26. Ardawi MS, Qari MH, Rouzi AA et al. (2011) Vitamin D status in relation to obesity, bone mineral density, bone turnover markers and vitamin $\mathrm{D}$ receptor genotypes in healthy Saudi pre- and postmenopausal women. Osteoporos Int 22, 463-475.

27. Al Faraj S \& Al Mutairi K (2003) Vitamin D deficiency and chronic low back pain in Saudi Arabia. Spine (Phila Pa 1976) 28, 177-179.

28. Abokrysha NT (2012) Vitamin D deficiency in women with fibromyalgia in Saudi Arabia. Pain Med 13, 452-458.

29. Racinais S, Hamilton B, Li CK et al. (2010) Vitamin D and physical fitness in Qatari girls. Arch Dis Child 95, 854-855.

30. Meguid NA, Hashish AF, Anwar M et al. (2010) Reduced serum levels of 25-hydroxy and 1,25-dihydroxy vitamin D in Egyptian children with autism. J Altern Complement Med 16, 641-645.

31. Lips P (2010) Worldwide status of vitamin D nutrition. $J$ Steroid Biochem Mol Biol 121, 297-300.

32. El Baba K, Zantout MS, Akel R et al. (2011) Seasonal variation of vitamin $\mathrm{D}$ and $\mathrm{HbA}(1 \mathrm{c})$ levels in patients with type 1 diabetes mellitus in the Middle East. Int J Gen Med $\mathbf{4}$, 635-638.

33. Mithal A, Wahl DA, Bonjour JP et al. (2009) Global vitamin D status and determinants of hypovitaminosis D. Osteoporos Int 20, 1807-1820.

34. Reid IR, Gallagher DJ \& Bosworth J (1986) Prophylaxis against vitamin $D$ deficiency in the elderly by regular sunlight exposure. Age Ageing 15, 35-40.

35. Fonseca V, Tongia R, El-Hazmi M et al. (1984) Exposure to sunlight and vitamin D deficiency in Saudi Arabian women. Postgrad Med J 60, 589-591. 